\title{
Primary aldosteronism: a common cause of resistant hypertension
}

\author{
Gregory A. Kline MD, Ally P.H. Prebtani BScPhm MD, Alexander A. Leung MD, Ernesto L. Schiffrin CM MD PhD
}

Cite as: CMAJ 2017 June 5;189:E773-8. doi: 10.1503/cmaj.161486

$\mathbf{R}$ esistant or difficult-to-control hypertension is a problem that may affect as many as $13 \%$ of all persons with hypertension. ${ }^{1}$ It is estimated that more than 6 million (22.6\%) of adults in Canada have hypertension, but less than two-thirds have it adequately controlled despite conventional strategies for treatment. ${ }^{2}$ Uncontrolled hypertension may arise from nonadherence to medication, selection of suboptimal treatment regimens and/or the presence of unidentified secondary causes. It is frustrating for both the patient and treating physician. Patients may embark upon a series of variably successful approaches with different drug classes. We review the accumulating epidemiologic evidence on primary aldosteronism and hypertension that is resistant to treatment. We offer a pragmatic approach to diagnosis for generalist physicians. Although no randomized controlled trials (RCTs) have reported a mortality benefit to screening or treatment for primary aldosteronism, multiple case-control, registry-based and systematic reviews of existing data may be used to construct a coherent, evidence-informed approach to diagnosis and treatment (Box 1). Detection of primary aldosteronism may allow disease-specific treatment that could improve rates of blood pressure control ${ }^{3}$ and may reduce the morbidity associated with resistant hypertension. ${ }^{4}$

\section{What is primary aldosteronism?}

Primary aldosteronism (called Conn syndrome for many years afterJerome Conn who first described it in $1955^{5}$ ) refers to the presence of a benign adrenocortical mass secreting aldosterone in a relatively autonomous fashion, often causing severe hypertension and hypokalemia. In the years that followed the original

\section{Box 1: Evidence used in this review}

We searched MEDLINE databases using combinations of the terms "aldosteronism," "resistant hypertension," "refractory hypertension," "prevalence," "review" and "guidelines." This search yielded numerous citations from within the past 15 years. We focused on the most recent publications, systematic reviews, guideline statements and highly cited articles. We focused on articles that included the largest numbers of patients, those that were conducted in a primary care setting and pertinent guidelines (e.g., from the Endocrine Society and Hypertension Canada).

\section{KEY POINTS}

- Difficult-to-control hypertension should trigger testing for primary aldosteronism.

- Measurement of aldosterone-to-renin ratio (ARR) is the preferred diagnostic test.

- Patients with high ARR who are potential candidates for surgical adrenalectomy and those with severe hypertension for whom discontinuation of antihypertensive drugs would be dangerous should be referred to a hypertension specialist for assessment.

- Patients with very severe hypertension who may not tolerate drug adjustment for ARR measures should also be assessed by a hypertension specialist.

- Patients who cannot be considered for adrenalectomy may consider an empiric trial of spironolactone or eplerenone for blood pressure control.

- If a normal or negative result for ARR testing is reported yet clinical suspicion of primary aldosteronism is high, repeating the test is appropriate after the patient has stopped taking all angiotensinconverting-enzyme-inhibitors, angiotensin receptor blockers, dihydropyridine calcium-channel blockers and/or diuretics for at least two weeks, to maximize test sensitivity; use of $\alpha$-blockers or non-dihydropyridine calcium-channel blockers may be necessary to control blood pressure in the interim.

description, it was quickly recognized that primary inappropriate aldosterone hypersecretion could be due to either an adrenal mass or bilateral hyperplasia of the adrenals.

Aldosterone is a salt-retaining hormone secreted by the zona glomerulosa layer of the adrenal cortex. It is secreted primarily in response to the effect of renin via angiotensin II, although pituitary-derived adrenocorticotropin hormone has a smaller, secondary stimulatory effect, as does an elevated serum potassium concentration. Aldosterone facilitates sodium resorption, and potassium and hydrogen secretion at the principal cells of the distal tubule and collecting duct. Resorption of sodium is considered to be the primary mechanism for an associated rise in blood pressure observed with activation of the mineralocorticoid receptor. Aldosterone also exerts effects on blood vessels, leading to remodelling, fibrosis and endothelial dysfunction, and on the heart, inducing cardiac fibrosis and hypertrophy.

It has been shown that hypokalemia (the traditional clue to the diagnosis of aldosteronism) is only present in less than $20 \%$ 
of cases; ${ }^{6}$ more likely with an underlying adrenal adenoma as the cause. ${ }^{7}$ Very uncommon familial forms of primary aldosteronism may be seen in a pediatric or adolescent patient ${ }^{8}$ but most patients present in adulthood.

In primary aldosteronism, there are many potential pathologic processes involved. These include either somatic ${ }^{9}$ or germline ${ }^{10}$ mutations in the genes for adrenocortical potassium channels, and ectopic hormone receptors. ${ }^{11}$ Some recent compelling evidence has suggested that there is a possibility of an independent adipose-cell-secreted ligand that drives aldosterone synthesis and secretion, ${ }^{12}$ potentially explaining the link between obesity-related resistant hypertension and aldosterone excess. ${ }^{13}$

\section{How common is primary aldosteronism?}

A 2004 review of estimates of prevalence of primary aldosteronism from five continents ${ }^{14}$ concluded that primary aldosteronism is more prevalent in modern populations of patients with hypertension than previously thought. Among patient cohorts with resistant hypertension, primary aldosteronism may be present in $10 \%$ to $20 \%,{ }^{15,16}$ and among less-selected populations of patients with mild to moderate hypertension (e.g., as may be typical of primary care) the prevalence is reported at $1 \%$ to $6 \% .{ }^{17} \mathrm{~A}$ screening study for primary aldosteronism in a primary care environment in Sweden reported a prevalence of 5.5\% among 200 patients who were newly diagnosed with hypertension. ${ }^{18}$

As yet, there are no specific geographic or racial markers of increased susceptibility, with broadly similar reports of prevalence for primary aldosteronism now available from countries representing a full spectrum of ethnic diversity. ${ }^{14,19,20}$ However, interpretation of these reports is limited by differences in the biochemical definition of primary aldosteronism between centres. A recently published systematic review of studies involving over 42000 patients concluded that reports of prevalence for primary aldosteronism of $3 \%$ to $13 \%$ in primary care and $1 \%$ to $30 \%$ in referral centres were too heterogeneous in nature to allow calculation of a single prevalence point estimate. ${ }^{21}$ Nonetheless, the consistent message is that primary aldosteronism is common enough and has sufficiently specific treatment options to justify more frequent diagnostic consideration in primary care (Box 2).

\section{Why is it important to diagnose primary aldosteronism?}

Evidence from case-control and registry studies suggests that patients with primary aldosteronism experience higher rates of negative health outcomes than patients with essential hypertension. A case-control study conducted in France that involved 124 patients diagnosed with primary aldosteronism during a three-year period, who were matched for age, gender, and systolic and diastolic blood pressure with 465 patients with essential hypertension, found that patients with primary aldosteronism had increased odds of having a stroke, nonfatal myocardial infarction or atrial fibrillation (for stroke: odds ratio $[\mathrm{OR}] 4.2,95 \%$ confidence interval $[\mathrm{Cl}]$ 2.0-8.6; for nonfatal myocardial infarction: OR 6.5, 95\% Cl 1.5-27.4; for atrial fibrillation: OR $12.1,95 \% \mathrm{Cl} 3.2-45.2) .{ }^{26} \mathrm{~A}$ retrospective study of 270 patients with primary aldosteronism matched $1: 3$ with 810 patients with essential hypertension and followed for hypertension-related events over 12 years reported a total cardiovascular event rate of $22.6 \%$ among the patients with primary aldosteronism compared with $12.7 \%$ among those with essential hypertension (OR 2.0, $95 \% \mathrm{Cl} 1.4-2.8) .{ }^{28} \mathrm{~A}$ retrospective cross-sectional study involving patients in six centres in Germany reported that cardiovascular complications, in particular, were more common in hypokalemic patients with primary aldosteronism compared with normokalemic patients, ${ }^{29}$ which suggests that the presence of hypokalemia in primary aldosteronism may portend a worse prognosis.

Primary aldosteronism appears to be associated with a hyperfiltration renal injury ${ }^{30}$ that may not be fully appreciated until after disease-specific therapy is instituted. ${ }^{31}$ Smaller studies have also linked primary aldosteronism to a higher risk of left ventricular hypertrophy, ${ }^{32}$ enhanced vascular stiffness, ${ }^{33}$ vascular dissection, ${ }^{34}$ development of type 2 diabetes $^{35}$ and poorer quality of life ${ }^{36}$ compared with essential hypertension. A study of 3428 patients in a Southern California database reported an $18 \%$ prevalence of sleep apnea in patients with primary aldosteronism, significantly higher than a prevalence of $9 \%$ in those without primary aldosteronism, ${ }^{37}$ suggesting a co-association of two conditions already linked with high risk of cardiovascular disease. Cardiovascular complications in patients with primary aldosteronism occur because effects of inappropriate elevation of circulating aldosterone acting through mineralocorticoid receptors on the heart, blood vessels and kidney. ${ }^{38,39}$ The detrimental effect of aldosterone excess (along with high salt intake) appears to lead to vascular smooth muscle prolif-

\section{Box 2: Studies reporting prevalence of primary}

aldosteronism, determined prospectively, by patient setting* and country

$\begin{array}{llcc}\text { Country in } & \text { Reported } \\ \text { which study } & \begin{array}{c}\text { prevalence of } \\ \text { primary } \\ \text { aldosteronism, }\end{array} \\ \text { Setting } & \begin{array}{l}\text { No. of } \\ \text { patients }\end{array} & \text { conducted } & \%\end{array}$

Unselected/primary care hypertension

$\begin{array}{lclc}\text { Loh K et al. }{ }^{19} & 350 & \text { Singapore } & 5 \\ \text { Fogari et al. }{ }^{17} & 3000 & \text { Italy } & 5.9 \\ \text { Omura et al. }{ }^{20} & 1020 & \text { Japan } & 6.0\end{array}$

Referred to specialty hypertension clinic/resistant hypertension

\begin{tabular}{|c|c|c|}
\hline Rossi et al. ${ }^{6}$ & 1125 & Italy \\
\hline Lim et al. ${ }^{22}$ & 465 & UK \\
\hline Abdelhamid et al. ${ }^{23}$ & 3900 & Germany \\
\hline Stowasser et al. ${ }^{24}$ & 300 & Australia \\
\hline Yin et al. ${ }^{25}$ & 313 & China \\
\hline Milliez et al. ${ }^{26}$ & 5438 & France \\
\hline Matrozova et al. ${ }^{27}$ & 376 & Bulgaria \\
\hline Strauch et al. ${ }^{15}$ & 402 & $\begin{array}{l}\text { Czech } \\
\text { Republic }\end{array}$ \\
\hline
\end{tabular}

*Minimum of 300 participants.

†Extremely restrictive definition of primary aldosteronism. 
eration and fibrosis, along with impaired vascular-endothelial vasodilatory function. ${ }^{40,41}$

Many studies of primary aldosteronism and associated clinical outcomes are potentially confounded by their retrospective design, referral bias and use of surrogate cardiovascular risk markers. However, given that undifferentiated resistant hypertension is already known to be associated with a high degree of morbidity and excess premature death, ${ }^{42,43}$ the cumulative evidence of additive health risks of excess aldosterone plus resistant hypertension supports a strong case for early consideration of testing for primary aldosteronism in patients with difficult-to-control hypertension or early cardiovascular complications (Box 3).

\section{How is primary aldosteronism diagnosed?}

The hallmark of primary aldosteronism is elevated levels of plasma aldosterone combined with low levels of renin. Normally, the production of renin by the renal juxtaglomerular apparatus leads to the generation of angiotensin I that is then converted to angiotensin II, which eventually stimulates aldosterone synthesis and secretion. When aldosterone is produced autonomously and inappropriately by one or both adrenal glands, normal negative feedback leads to profound suppression of renin. This high-aldosterone/lowrenin state is best captured by measuring plasma aldosterone-torenin ratio (ARR). A high ARR is typically the first clue, especially in the normokalemic patient, to the presence of primary aldosteronism and is currently recommended as the preferred test. ${ }^{44}$

\section{Who should be considered for testing?}

The guideline from Hypertension Canada recommends targeted testing for hypertensive patients with features suggestive of primary aldosteronism (Box 4) based on grade-D level evidence (consensus). ${ }^{46}$ Testing is particularly useful for patients who would be potential candidates for adrenalectomy if a unilateral adrenal aldosteronoma were to be found. Patients who are already known to be poor surgical candidates may not require extensive investigation. Empiric treatment with mineralocorticoid receptor antagonists (such as spironolactone or eplerenone) may be considered as a preferred alternative..$^{47,48}$

\section{What are the important considerations for ARR testing?}

Most patients being screened for primary aldosteronism will already be taking antihypertensive drugs. Debate continues about the exact role and importance of avoiding drug interference in ARR testing. ${ }^{49,50}$ At minimum, to avoid false-negative results for the test, patients must refrain from taking spironolactone for at least four to six weeks prior and supplemented with potassium (taken orally) if hypokalemic. Ideally, patients should follow an ad lib or high-salt diet for two days before testing; ${ }^{51}$ patients may need specific instruction because many will have been counselled previously to limit sodium intake. Blood samples should be taken with the patient seated and before 10:00 am, although fasting is not required.
Like most endocrine tests, the numeric determination of what constitutes a normal versus abnormal result for an ARR test is often a compromise between acceptable sensitivity and specificity for the disease in question, and any given numerical test cutoff will depend to some extent upon the way the test is reported by an individual laboratory. ${ }^{45}$ Box 4 provides suggested ARR interpretation levels that take local laboratory methodology into account, along with an indication of what may be considered a "weakly positive" or "strongly positive" test result. Discussion with the local laboratory director may be necessary to determine which line will be most applicable to the practitioner's setting. If a "normal or negative" result for ARR testing is reported yet clinical suspicion of primary aldosteronism is high, repeating the test is appropriate after the patient has stopped taking all angiotensinconverting-enzyme (ACE) inhibitors, angiotensin receptor blockers, dihydropyridine calcium-channel blockers and/or diuretics for at least two weeks, to maximize the sensitivity of the test. ${ }^{44}$ Prescription of $\alpha$-blockers or non-dihydropyridine calcium-channel blockers may be necessary to control blood pressure in the interim.

\section{What should be done for patients with a high result for ARR testing?}

After a positive ARR test result, biochemical confirmatory testing is frequently recommended; 44 consultation with an expert in hypertension should be considered because confirmatory testing can be challenging to perform and difficult to interpret. However, confirmatory testing may be unnecessary for highly probable cases, such as those with spontaneous hypokalemia or extremely elevated ARRs, ${ }^{52,53}$ which are features strongly predictive of aldosterone-producing adrenal adenoma. ${ }^{7}$ Proceeding with further localization investigations should be guided by patient preference, feasibility of surgery and availability of specialized endocrine testing facilities once there is biochemical confirmatory testing of primary aldosteronism. In patients with unilateral adrenal disease, adrenalectomy may be curative. In patients unwilling or unable to undergo surgery, or those with bilateral adrenal hyperplasia, empiric therapy with an aldosterone antagonist such as spironolactone or eplerenone should be considered.

Box 3: Increased risk of complications associated with primary aldosteronism compared with essential hypertension
- Stroke $^{26}$
- Nonfatal myocardial infarction ${ }^{26}$
- Atrial fibrillation ${ }^{26}$
- Albuminuria ${ }^{30}$
- Chronic kidney disease ${ }^{30}$
- Left ventricular hypertrophy ${ }^{32}$
- Vascular stiffness, dissection 33,34
- Metabolic syndrome/type 2 diabetes $^{35}$
- Obstructive sleep apnea ${ }^{37}$
- Anxiety/depression ${ }^{36}$ 
Spironolactone has been in clinical use for over 50 years and is a potent blocker of the mineralocorticoid receptor. As an older drug, it has never been studied in a large prospective controlled trial for essential hypertension, but clinical experience has shown repeatedly that this agent is highly effective at controlling blood pressure in those with primary aldosteronism, ${ }^{54}$ elevated $\mathrm{ARR}^{48,55}$ and resistant hypertension..$^{45}$ It is inexpensive and widely available. Antiandrogen activity leading to symptoms such as gynecomastia occurs in as many as $10 \%$ of older men who are taking $25 \mathrm{mg}$ per day, ${ }^{56}$ with higher rates at larger dosages. As an antiandrogen, it should not be offered to women of child-bearing age without contraception. After starting spironolactone therapy, monitoring of serum creatinine and electrolyte levels is suggested to watch for hyperkalemia, particularly in those patients with renal impairment (estimated glomerular filtration rate of $\left.<40 \mathrm{~mL} / \mathrm{min} / \mathrm{m}^{2}\right)^{57}$ or those who are taking other drugs that predispose to hyperkalemia, such as ACE inhibitors or angiotensin receptor blockers. ${ }^{58}$ Eplerenone is newer and has much less propensity to block the androgen receptor and thus cause less gynecomastia; ${ }^{59}$ however, it is more expensive than spironolactone at present and less potent.

As many as $97 \%$ of patients with primary aldosteronism may achieve blood pressure control following either surgery or targeted medical treatment, ${ }^{60}$ and evidence from two small prospective studies suggests equal efficacy in the prevention or regression of complications from primary aldosteronism. ${ }^{61,62} \mathrm{~A}$ meta-analysis of studies involving patients undergoing adrenalectomy that examined surgical outcomes for primary aldosteronism reported that $52 \%(95 \% \mathrm{Cl} 44 \%-60 \%)$ of these patients $(n=$ 1685) were able to achieve drug-free normotension. ${ }^{3}$ Further prospective studies are needed to determine whether surgical (removing aldosterone excess) or medical treatment (blocking aldosterone excess) is superior for ameliorating the hypertensive and tissue consequences of this disease.

\section{What is the role of primary care in case finding for primary aldosteronism?}

Primary aldosteronism has been shown to be a serious and common cause of resistant hypertension worldwide. A diagnosis of primary aldosteronism frequently follows a lengthy history of hypertension. Prospective studies involving patients undergoing treatment for primary aldosteronism have indicated that many patients with primary aldosteronism have substantial chronic renal injury that is uncovered by treatment following diagnosis, which appears to be irreversible even after correction of primary aldosteronism. ${ }^{31,63}$ This evidence points to an important role for primary care practitioners to become more involved in the selection of patients for primary aldosteronism testing in conducting the initial diagnostic test. Randomized controlled trials of screening for primary aldosteronism versus no screening are unlikely to be conducted; therefore, recommendations for practical incorporation of diagnostics for primary aldosteronism in routine care are needed now. Some clinical questions remain (see Box 5). However, for now, recognition of a diagnosis of primary aldosteronism will allow physicians to "put a name" on many difficult-to-treat cases of resistant hypertension and will pave the way for individualized disease-specific treatment.

\section{Conclusion}

Primary aldosteronism is now known to be a relatively common cause of resistant hypertension worldwide. Beyond its relation with uncontrolled blood pressure, it may play a tissue-specific

Box 4: Approach to investigating suspected primary aldosteronism

Indications for testing for primary aldosteronism recommended by Hypertension Canada ${ }^{46}$

- Uncontrolled hypertension (> 140/90 mm Hg) despite use of three drugs, one of which is a thiazide/thiazide-like diuretic

- Hypertension with hypokalemia induced by use of thiazide/thiazide-like diuretics ( $<3.0 \mathrm{mmol} / \mathrm{L}$ )

- Spontaneous hypokalemia with hypertension (<3.5 mmol/L)

- Hypertension with known adrenal mass

How to request testing for aldosterone-to-renin ratio ${ }^{45}$

- Patient should stop taking spironolactone or eplerenone for four to six weeks prior to testing.

- Patient should be instructed to follow a high-salt diet for two days prior to testing.

- If hypokalemic, the patient should receive oral potassium replacement to restore eukalemia.

- Plasma levels of aldosterone and renin should be requested, with sample collection occurring while the patient is seated and prior to $10: 00$ am (fasting is not required).

Interpretation of aldosterone-to-renin ratio*44

Method for measuring renin

Weak positive result for ARR

Strong positive result for ARR

Plasma renin activity $(\mathrm{ng} / \mathrm{mL} / \mathrm{h})$

$550-750$

$>750$

Renin concentration ( $\mathrm{mU} / \mathrm{L}$ )

$60-90$

$>90$

Renin concentration (ng/L)

$100-144$

$>144$

Note: $A R R=$ aldosterone-to-renin ratio.

*Dependent upon the method for renin measurement used by the local laboratory; however, standard reporting of aldosterone in $\mathrm{pmol} / \mathrm{L}$ is assumed. 


\section{Box 5: Unanswered questions}

- Does more aggressive or standardized screening for primary aldosteronim improve rates of blood pressure control among patients with resistant hypertension?

- What is the most cost-effective approach to the investigation of primary aldosteronism in Canada?

- What other clinical scenarios warrant consideration of a diagnosis of primary aldosteronism (e.g., obstructive sleep apnea)?

- Does a strategy of aldosterone antagonism improve morbidity or mortality in hypertensive patients compared with present treatments?

role in the adverse cardiovascular consequences that accompany resistant hypertension. For patients with a diagnosis of primary aldosteronism, disease-specific treatment is widely available, inexpensive and effective for control of blood pressure. Measurement of ARR for diagnosis of primary aldosteronism can be readily implemented and is a highly useful tool in primary and specialty care to facilitate the detection, diagnosis and treatment of this potentially remediable condition.

\section{References}

1. Persell SD. Prevalence of resistant hypertension in the United States, 20032008. Hypertension 2011;57:1076-80.

2. Padwal RS, Bienek A, McAlister FA, et al. Epidemiology of hypertension in Canada: an update. Can J Cardiol 2016;32:687-94.

3. Benham JL, Eldoma M, Khokhar B, et al. Proportion of patients with hypertension resolution following adrenalectomy for primary aldosteronism: a systematic review and meta-analysis. J Clin Hypertens (Greenwich) 2016;18:1205-12.

4. Rossi GP, Cesari M, Cuspidi C, et al. Long-term control of arterial hypertension and regression of left ventricular hypertrophy with treatment of primary aldosteronism. Hypertension 2013;62:62-9.

5. Conn JW. Presidential address. Transl Res 1955;45:3-17. Available: www.translationalres.com/article/0022214355900482/fulltext (accessed 2016 Dec. 13).

6. Rossi GP, Bernini G, Caliumi C, et al. A prospective study of the prevalence of primary aldosteronism in 1125 hypertensive patients. J Am Coll Cardiol 2006; 48:2293-300.

7. Küpers EM, Amar L, Raynaud A, et al. A clinical prediction score to diagnose unilateral primary aldosteronism. J Clin Endocrinol Metab 2012;97:3530-7.

8. Zennaro MC, Boulkroun S, Fernandes-Rosa F. Inherited forms of mineralocorticoid hypertension. Best Pract Res Clin Endocrinol Metab 2015;29:633-45.

9. Lenzini L, Rossitto G, Maiolino G, et al. A meta-analysis of somatic KCNJ5 K + channel mutations in 1636 patients with an aldosterone-producing adenoma. J Clin Endocrinol Metab 2015;100:E1089-95.

10. Murthy M, Xu S, Massimo G, et al. Role for germline mutations and a rare coding single nucleotide polymorphism within the KCNJ5 potassium channel in a large cohort of sporadic cases of primary aldosteronism. Hypertension 2014;63:783-9.

11. Mazzuco TL, Grunenwald S, Lampron A, et al. Aberrant hormone receptors in primary aldosteronism. Horm Metab Res 2010;42:416-23.

12. Ehrhart-Bornstein M, Lamounier-Zepter V, Schraven A, et al. Human adipocytes secrete mineralocorticoid-releasing factors. Proc Natl Acad Sci U SA 2003;100:14211-6.

13. Calhoun DA, Sharma K. The role of aldosteronism in causing obesity-related cardiovascular risk. Cardiol Clin 2010;28:517-27.

14. Mulatero P, Stowasser M, Loh KC, et al. Increased diagnosis of primary aldosteronism, including surgically correctable forms, in centers from five continents. J Clin Endocrinol Metab 2004;89:1045-50.

15. Strauch B, Zelinka T, Hampf M, et al. Prevalence of primary hyperaldosteronism in moderate to severe hypertension in the Central Europe region. J Hum Hypertens 2003;17:349-52.

16. Calhoun DA, Nishizaka MK, Zaman MA, et al. Hyperaldosteronism among black and white subjects with resistant hypertension. Hypertension 2002;40:892-6.

17. Fogari R, Preti P, Zoppi A, et al. Prevalence of primary aldosteronism among unselected hypertensive patients: a prospective study based on the use of an aldosterone/renin ratio above 25 as a screening test. Hypertens Res 2007;30:111-7.
18. Westerdahl C, Bergenfelz A, Isaksson A, et al. Primary aldosteronism among newly diagnosed and untreated hypertensive patients in a Swedish primary care area. Scand J Prim Health Care 2011;29:57-62.

19. Loh KC, Koay ES, Khaw MC, et al. Prevalence of primary aldosteronism among Asian hypertensive patients in Singapore. J Clin Endocrinol Metab 2000;85:2854-9.

20. Omura M, Saito J, Yamaguchi K, et al. Prospective study on the prevalence of secondary hypertension among hypertensive patients visiting a general outpatient clinic in Japan. Hypertens Res 2004;27:193-202.

21. Käyser SC, Dekkers T, Groenewoud HJ, et al. Study heterogeneity and estimation of prevalence of primary aldosteronism: a systematic review and metaregression analysis. J Clin Endocrinol Metab. 2016;101:2826-35.

22. Lim PO, Dow E, Brennan G, et al. High prevalence of primary aldosteronism in the Tayside hypertension clinic population. J Hum Hypertens 2000;14:311-5.

23. Abdelhamid S, Muller-Lobeck H, Pahl S, et al. Prevalence of adrenal and extraadrenal Conn syndrome in hypertensive patients. Arch Intern Med 1996;156:1190-5.

24. Stowasser M, Gordon RD, Gunasekera TG, et al. High rate of detection of primary aldosteronism, including surgically treatable forms, after "non-selective" screening of hypertensive patients. J Hypertens 2003;21:2149-57.

25. Yin G, Zhang S, Yan L, et al. Effect of age on aldosterone/renin ratio (ARR) and comparison of screening accuracy of ARR plus elevated serum aldosterone concentration for primary aldosteronism screening in different age groups. Endocrine 2012;42:182-9.

26. Milliez P, Girerd X, Plouin PF, et al. Evidence for an increased rate of cardiovascular events in patients with primary aldosteronism. J Am Coll Cardiol 2005;45:1243-8.

27. Matrozova JA, Zacharieva SZ, Kirilov GG, et al. Prevalence of primary aldosteronism among Bulgarian hypertensive patients. Central Eur J Med 2010;5:399-405.

28. Mulatero P, Monticone S, Bertello C, et al. Long-term cardio- and cerebrovascular events in patients with primary aldosteronism. J Clin Endocrinol Metab 2013;98:4826-33.

29. Born-Frontsberg E, Reincke M, Rump LC, et al. Cardiovascular and cerebrovascular comorbidities of hypokalemic and normokalemic primary aldosteronism: results of the German conn's registry. J Clin Endocrinol Metab 2009;94:1125-30.

30. Kramers BJ, Kramers C, Lenders JWM, et al. Effects of treating primary aldosteronism on renal function. J Clin Hypertens (Greenwich) 2017;19:290-5.

31. Iwakura $\mathrm{Y}$, Morimoto $\mathrm{R}, \mathrm{Kudo} \mathrm{M}$, et al. Predictors of decreasing glomerular filtration rate and prevalence of chronic kidney disease after treatment of primary aldosteronism: renal outcome of 213 cases. J Clin Endocrinol Metab 2014;99:1593-8.

32. Tanabe A, Naruse M, Naruse K, et al. Left ventricular hypertrophy is more prominent in patients with primary aldosteronism than in patients with other types of secondary hypertension. Hypertens Res 1997;20:85-90.

33. Mahmud A, Feely J. Aldosterone-to-renin ratio, arterial stiffness, and the response to aldosterone antagonism in essential hypertension. Am J Hypertens 2005;18:50-5.

34. Ahmed SH, Husain NM, Khawaja SN, et al. Is primary hyperaldosteronism a risk factor for aortic dissection? Cardiology 2007;108:48-50.

35. Hanslik G, Wallaschofski H, Dietz A, et al. Increased prevalence of diabetes mellitus and the metabolic syndrome in patients with primary aldosteronism of the German Conn's Registry. Eur J Endocrinol 2015;173:665-75.

36. Ahmed AH, Gordon RD, Sukor N, et al. Quality of life in patients with bilateral primary aldosteronism before and during treatment with spironolactone and/or amiloride, including a comparison with our previously published results in those with unilateral disease treated surgically. J Clin Endocrinol Metab 2011;96:2904-11.

37. Sim JJ, Yan EH, Liu IL, et al. Positive relationship of sleep apnea to hyperaldosteronism in an ethnically diverse population. J Hypertens 2011;29:1553-9.

38. Ferrario CM, Schiffrin EL. Role of mineralocorticoid receptor antagonists in cardiovascular disease. Circ Res 2015;116:206-13.

39. Briet M, Schiffrin EL. Aldosterone: effects on the kidney and cardiovascular system. Nat Rev Nephrol 2010;6:261-73.

40. Pruthi D, Mccurley A, Aronovitz M, et al. Aldosterone promotes vascular remodeling by direct effects on smooth muscle cell mineralocorticoid receptors. Arterioscler Thromb Vasc Biol 2014;34:355-64.

41. Chou $\mathrm{CH}$, Chen $\mathrm{YH}$, Hung $\mathrm{CS}$, et al. Aldosterone impairs vascular smooth muscle function: from clinical to bench research. J Clin Endocrinol Metab 2015;100:4339-47.

42. Pierdomenico SD, Lapenna D, Bucci A, et al. Cardiovascular outcome in treated hypertensive patients with responder, masked, false resistant, and true resistant hypertension. Am J Hypertens 2005;18:1422-8.

43. Irvin MR, Booth JN, Shimbo D, et al. Apparent treatment-resistant hypertension and risk for stroke, coronary heart disease, and all-cause mortality. J Am Soc Hypertens 2014;8:405-13.

44. Funder JW, Carey RM, Mantero F, et al. The management of primary aldosteronism: case detection, diagnosis, and treatment: an endocrine society clinical practice guideline. J Clin Endocrinol Metab 2016;101:1889-916.

45. Rehan M, Raizman JE, Cavalier E, et al. Laboratory challenges in primary aldosteronism screening and diagnosis. Clin Biochem 2015;48:377-87.

46. Leung AA, Nerenberg K, Daskalopoulou SS, et al. Hypertension Canada's 2016 Canadian hypertension education program guidelines for blood pressure mea- 
surement, diagnosis, assessment of risk, prevention, and treatment of hypertension. Can J Cardiol 2016;32:569-88.

47. Williams B, Macdonald TM, Morant S, et al. Spironolactone versus placebo, bisoprolol, and doxazosin to determine the optimal treatment for drug-resistant hypertension (PATHWAY-2): a randomised, double-blind, crossover trial. Lancet 2015; 386:2059-68.

48. Lim PO, Jung RT, MacDonald TM. Raised aldosterone to renin ratio predicts antihypertensive efficacy of spironolactone: a prospective cohort follow-up study. Br J Clin Pharmacol 1999;48:756-60.

49. Browne GA, Griffin TP, O'Shea PM, et al. $\beta$-Blocker withdrawal is preferable for accurate interpretation of the aldosterone-renin ratio in chronically treated hypertension. Clin Endocrinol (Oxf) 2016;84:325-31.

50. Gallay BJ, Ahmad S, Xu L, et al. Screening for primary aldosteronism without discontinuing hypertensive medications: plasma aldosterone-renin ratio. Am J Kidney Dis 2001;37:699-705.

51. Baudrand R, Guarda FJ, Torrey J, et al. Dietary sodium restriction increases the risk of misinterpreting mild cases of primary aldosteronism. J Clin Endocrinol Metab 2016;101:3989-96

52. Kline GA, Pasieka JL, Harvey A, et al. High-probability features of primary aldosteronism may obviate the need for confirmatory testing without increasing false-positive diagnoses. J Clin Hypertens (Greenwich) 2014;16:488-96.

53. Nanba K, Tamanaha T, Nakao K, et al. Confirmatory testing in primary aldosteronism. J Clin Endocrinol Metab 2012;97:1688-94.

54. Brown JJ, Davies DL, Ferriss JB, et al. Comparison of surgery and prolonged spironolactone therapy in patients with hypertension, aldosterone excess, and low plasma renin. BMJ 1972;2:729-34.

55. Mahmud A, Mahgoub M, Hall M, et al. Does aldosterone-to-renin ratio predict the antihypertensive effect of the aldosterone antagonist spironolactone? Am J Hypertens 2005;18:1631-5.

56. Pitt B., Zannad F, Remme WJ, et al. The effect of spironolactone on morbidity and mortality in patients with severe heart failure. Randomized Aldactone Evaluation Study Investigators. N Engl J Med 1999;341:709-17.

57. Schjoedt KJ, Rossing K, Juhl TR, et al. Beneficial impact of spironolactone in diabetic nephropathy. Kidney Int 2005;68:2829-36.

58. Juurlink DN, Mamdani MM, Lee DS, et al. Rates of hyperkalemia after publication of the Randomized Aldactone Evaluation Study. N Engl J Med 2004;351:543-51.

59. Barnes BJ, Howard PA. Eplerenone: a selective aldosterone receptor antagonist for patients with heart failure. Ann Pharmacother 2005;39:68-76.

60. Kline GA, Pasieka JL, Harvey A, et al. Medical or surgical therapy for primary aldosteronism: post-treatment follow-up as a surrogate measure of comparative outcomes. Ann Surg Oncol 2013;20:2274-8.

61. Catena C, Colussi G, Nadalini E, et al. Cardiovascular outcomes in patients with primary aldosteronism after treatment. Arch Intern Med 2008;168:80-5.

62. Sechi LA, Novello M, Lapenna R, et al. Long-term renal outcomes in patients with primary aldosteronism. JAMA 2006;295:2638-45.

63. Tanase-Nakao K, Naruse M, Nanba K, et al. Chronic kidney disease score for predicting postoperative masked renal insufficiency in patients with primary aldosteronism. Clin Endocrinol (Oxf) 2014;81:665-70.
Competing interests: Ally Prebtani has received consultant and speaker fees from Servier and is the Chair, Endocrine Section, Hypertension Canada, Clinical Practice Guidelines. Ernesto Schiffrin has received grants from the Canadian Institutes of Health Research and Servier France. He has received lecture fees from Servier Canada, and consultant and lecture fees from Novartis US. No other competing interests were declared.

This article was solicited and has been peer reviewed.
Affiliations: Department of Endocrinology (Kline, Leung), University of Calgary, Calgary, Alta.; Department of Internal Medicine, Endocrinology and Metabolism (Prebtani), McMaster University, Hamilton, Ont.; Department of Medicine (Schiffrin), Jewish General Hospital and Lady Davis Research Institute, McGill University, Montréal, Que.

Contributors: All of the authors contributed substantially to the design and writing of the manuscript. Gregory Kline drafted the article. All of the authors critically revised the manu- script for important intellectual content, gave final approval to the version to be published and agreed to be accountable for all aspects of the work.

Funding: Alexander Leung is supported by the Hypertension Canada New Investigator Award. Ernesto Schiffrin is supported by a Tier 1 Canada Research Chair funded by the Canadian Institutes of Health Research/Government of Canada program.

Correspondence to: Gregory Kline, gregory. kline@ahs.ca 